Pacific Journal of Mathematics

MAPS WHICH INDUCE THE ZERO MAP ON HOMOTOPY 


\title{
MAPS WHICH INDUCE THE ZERO MAP ON HOMOTOPY
}

\author{
DONALD W. KAHN
}

The work of Eilenberg and MacLane shows that a map from one space to another may induce the zero map on homotopy groups, yet be essential. The purpose of this paper is to give a characterization of such maps in terms of Postnikov decompositions of the spaces. As applications, we consider what additional information is needed to make such a map nullhomotopic, and we prove a proposition concerning Chern classes.

In his paper [5], J.H.C. Whitehead characterized those maps which induce isomorphisms on homotopy groups by showing that (for reasonable spaces) they are exactly the homotopy equivalences. The more modest goal of this paper is to give a characterization of the maps which induce the zero homomorphism on homotopy groups. Here the result is not so simple, and the answer is given in terms of the Postnikov systems of the spaces involved. These maps occur in various cases, but for the purpose of illustration we consider the following two:

(1) The question of when such a map is null-homotopic and

(2) the example when the image space is $B_{U}$, the classifying space for the infinite unitary group.

Throughout this note, all spaces have the homotopy-type of a 1connected $C W$-complex. All spaces have base points, which are preserved by maps and homotopies.

1. We shall use the following definition of a Postnikov system.

Definition. A Postnikov system for $X$ is a family $\left\{X_{n}, P_{n}, \pi_{n}\right\}$, $n>0$, where $X_{n}$ is a space and $P_{n}: X \rightarrow X_{n}, \pi_{n}: X_{n} \rightarrow X_{n-1}$, such that

(1) if $X$ is $(m-1)$-connected, $X_{i}=$ point, $i<m$,

(2) $P_{n}$ is an $n$-equivalence,

(3) $\pi_{n}$ defines principal fibre space $^{1}$, with fibre $K\left(\pi_{n}(X), n\right)$, and

(4) $\pi_{n} P_{n} \simeq P_{n-1}$.

It is well-known that any $X$ having the homotopy type of a 1connected complex has a Postnikov system. ${ }^{2}$ Furthermore, if $f: X \rightarrow X^{\prime}$, where $X$ and $X^{\prime}$ have as Postnikov systems $\left\{X_{n}, P_{n}, \pi_{n}\right\}$ and $\left\{X_{n}^{\prime}, P_{n}^{\prime}, \pi_{n}^{\prime}\right\}$, then there are maps $f_{n}: X_{n} \rightarrow X_{n}^{\prime}$ such that

(1) $\pi_{n}^{\prime} \cdot f_{n}=f_{n-1} \cdot \pi_{n}$ and

(2) $f_{n} \cdot P_{n} \simeq P_{n}^{\prime} \cdot f$. (See [2]).

Received April 7, 1964. Work partially supported by contract NONR $266(57)$.

1 With no loss of generality, we may take it to be a principal fibre bundle.

2 If $X$ was not 1-connected, but $\pi_{1}(X)$ was abelian, this would still hold. 
It is easy to see that any two such $f_{n}$ are necessarily homotopic, and we refer to any such map as an induced map for $f$.

Theorem 1. Let $X$ and $X^{\prime}$ have Postnikov systems $\left\{X_{n}, P_{n}, \pi_{n}\right\}$ and $\left\{X_{n}^{\prime}, P_{n}^{\prime}, \pi_{n}^{\prime}\right\}$. Let $f: X \rightarrow X^{\prime}$ have induced maps $f_{n}: X_{n} \rightarrow X_{n}^{\prime}$. If for $i>N>1, f_{i}: \pi_{i}(X) \rightarrow \pi_{i}\left(X^{\prime}\right)$ is the zero map, then for each $i>N$, there is a map $h_{i}: X_{i-1} \rightarrow X_{i}^{\prime}$ such that the diagram

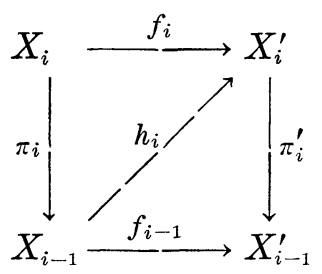

is homotopy commutative.

Proof. Let $k^{\prime i+1}$ denote the $k$-invariant for the fibration $\pi_{i}^{\prime}: X_{i}^{\prime} \rightarrow$ $X_{i-1}^{\prime}$. Up to sign, $k^{\prime i+1}$ is the obstruction to forming a cross-section to this fibration, or an equivalent one over a base space which is actually a complex. The obstruction to lifting $f_{i-1}$ to $X_{i}^{\prime}$ is then $f_{i-1}^{*} k^{\prime i+1}$. But as $f_{i-1}^{*} k^{\prime i+1}=f_{i}^{c} k^{i+1}$, where $f_{i}^{c}$ is the coefficient homomorphism (see [2]), we have $f_{i-1}^{*} k^{\prime i+1}=0$, for $i>N$. Hence, when $i>N$, there is a map $\bar{h}_{i}: X_{i-1} \rightarrow X_{i}^{\prime}$ with $\pi_{i}^{\prime} \bar{h}_{i}=f_{i-1}$.

Consider the maps $f_{i}$ and $\bar{h}_{i} \pi_{i}$. Because $\pi_{i}^{\prime} f_{i}=f_{i-1} \pi_{i}=\pi_{i}^{\prime} \bar{h}_{\imath} \pi_{i}$, there is a map: $d: X_{i} \rightarrow K\left(\pi_{i}\left(X_{i}^{\prime}\right), i\right)$ such that

$$
\mu \cdot\left(d \times \bar{h}_{i} \pi_{i}\right)=f_{\imath}
$$

where $\mu: K\left(\pi_{\imath}\left(X_{i}\right), i\right) \times X_{\imath} \rightarrow X_{i}$ is the usual action of the fibre. If $x \in X_{i}, d(x)$ is the unique element of $K\left(\pi_{i}\left(X_{i}\right), i\right)$ such that $f_{i}(x)=$ $d(x) \cdot\left(\bar{h}_{i} \pi_{i}(x)\right)$.

Now $\bar{h}_{i}$ maps the base point in the space $X_{i-1}$ into the base point in the fibre over the base point in $X_{i-1}^{\prime}$. Then $\bar{h}_{i} \cdot \pi_{i}$ maps the fibre in $\pi_{i}: X_{i} \rightarrow X_{i-1}$ into the identity, so that $d \mid K\left(\pi_{i}\left(X_{i}\right), i\right)=f_{i}$. Since $f_{i}$ induces the zero map on homotopy, the composition

$$
K\left(\pi_{i}\left(X_{i}\right), i\right) \stackrel{i}{\longrightarrow} X_{i} \stackrel{d}{\longrightarrow} K\left(\pi_{i}\left(X_{i}^{\prime}\right), i\right)
$$

is null-homotopic. Using the Serre sequence (see [4]) for the fibre space $\pi_{i}: X_{i} \rightarrow X_{i-1}$, we see that there is a map $\bar{d}$ so that

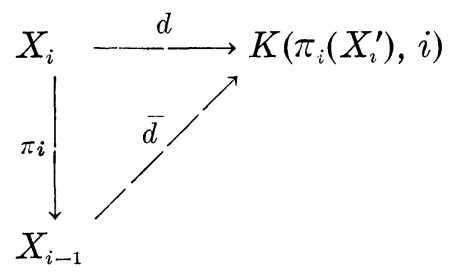


is homotopy commutative. Hence,

$$
\left(d \times \bar{h}_{i} \pi_{i}\right) \simeq\left(\bar{d} \pi_{i} \times \bar{h}_{i} \pi_{i}\right) \simeq\left(\bar{d} \times \bar{h}_{i}\right) \pi_{i},
$$

and then

$$
\mu\left(\bar{d} \times \bar{h}_{i}\right) \cdot \pi_{i} \simeq f_{i}
$$

while

$$
\pi_{i}^{\prime} \mu\left(\bar{d} \times \bar{h}_{i}\right)=\pi_{i}^{\prime} \bar{h}_{i}=f_{i-1} .
$$

Therefore, we set $h_{i}=\mu\left(\bar{d} \times \bar{h}_{i}\right)$, and the proof is complete.

Theorem 2. Let $X$ and $X^{\prime}$ have Postnikov systems $\left\{X_{n}, P_{n}, \pi_{n}\right\}$ and $\left\{X_{n}^{\prime}, P_{n}^{\prime}, \pi_{n}^{\prime}\right\}$. Let $f: X \rightarrow X^{\prime}$ with induced maps $f_{n}$.

$f$ induces the zero map in homotopy in all positive dimensions, if and only if for each $i>1$, there is a map $h_{i}: X_{i-1} \rightarrow X_{i}^{\prime}$ such that

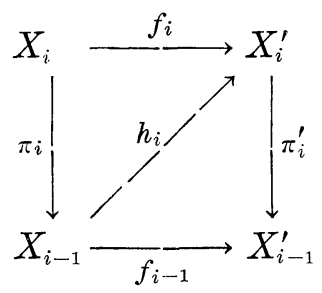

is homotopy commutative.

Proof. If $f$ induces the zero map, apply Theorem 1 with $N=1$.

For the converse, if $i \leqq n$, we identify $\pi_{i}(X)$ with $\pi_{i}\left(X_{i}\right)$ and the same for $X^{\prime}$. Then, we may identify $f_{i}$ with $\left(f_{n}\right)_{i}: \pi_{i}\left(X_{n}\right) \rightarrow \pi_{i}\left(X_{n}^{\prime}\right)$. But $f_{n \sharp}=\left(h_{n} \cdot \pi_{n}\right)_{\sharp}$, which is always zero in dimension $n$ because $\pi_{n}\left(X_{n-1}\right)=0$.

2. In general, if a map $f: X \rightarrow X^{\prime}$ induces the zero map on homotopy groups, it need not be null homotopic. (Eilenberg-MacLane spaces give many examples, and with slight modifications one may take $X=X^{\prime}$.) I will first consider conditions which insure that such maps are null-homotopic.

Proposition 1. Assume $X$ has the homotopy-type of a finitedimensional complex. Let $f: X \rightarrow X^{\prime}$. Suppose either

(1) $H^{n}\left(X ; \pi_{n}\left(X^{\prime}\right)\right)=0$, all $n$. (This for comparison)

or (2) $H^{n}\left(X_{n-1} ; \pi_{n}\left(X^{\prime}\right)\right)=0$, all $n$, and $f$ induces the zero map on homotopy.

Then $f$ is null-homotopic. 
Proof. It is sufficient to show that $P_{n}^{\prime} \cdot f \simeq 0$ for all $n$. The case of condition (1) is trivial. In case (2), $P_{n}^{\prime} \cdot f \simeq f_{n} \cdot P_{n} \simeq h_{n} \cdot \pi_{n} \cdot P_{n} \simeq$ $h_{n} \cdot P_{n-1} \cdot$ Assuming that $P_{n-1}^{\prime} \cdot f \simeq 0, f_{n-1} \cdot P_{n-1} \simeq 0$, then $\pi_{n}^{\prime} \cdot h_{n} \cdot P_{n-1} \simeq 0$. But then, by the Puppe sequence, $h_{n}$ comes from a map into the fibre of $\pi_{n}^{\prime}: X_{n}^{\prime} \rightarrow X_{n-1}^{\prime}$, which is null-homotopic by assumption.

REMARK. If there is other structure present, one can often say more. For example, let $f: X \rightarrow X^{\prime}$ be a homomorphism of $H$-spaces. Then if $X$ is $(m-1)$-connected, $f_{\sharp m}=0$, and $H^{n}\left(X ; \pi_{n}\left(X^{\prime}\right)\right)$ contains no primitive elements for $n>m$, then $f$ is null-homotopic.

For the next case, we need some notation. Suppose $X$ has finite homotopy groups. Denote by $\mathfrak{S}(X, n)$ the class of finite abelian groups (see [3]) generated by $\pi_{i}(X), i \leqq n$. In other words, $\mathfrak{c}(X, n)$ is the class of torsion groups whose $p$-components are zero for all primes which do not figure in the homotopy of $X_{n}$.

Proposition 2. Let $X$ have finite homotopy groups, and let $\xi$ be a $U$-bundle over $X$. Let $c_{i}(\xi) \in H^{2 i}(X ; Z)$ be the $i$ th. Chern class (see [1]). Then $c_{i}(\xi)$ is contained in a subgroup of $H^{2 i}(X ; Z)$ which belongs to $\mathfrak{C}(X ; 2 i-1)$.

Proof. Let $\xi$ be given as a map

$$
f_{\xi}: X \rightarrow B_{U} \text {. }
$$

$f_{\xi}$ must induce the zero map on homotopy groups. By Theorem 2, $\left(f_{\xi}\right)_{n}: X_{n} \rightarrow\left(B_{U}\right)_{n}$ factors through $X_{n-1}$. Now, the $i$ th universal Chern class lies in $H^{2 i}\left(\left(B_{U}\right)_{2 i} ; Z\right)$ so that $c_{i}(\xi) \in \pi_{2 i}^{*}\left(H^{2 i}\left(X_{2 i-1} ; Z\right)\right)$. But by (3), we know that

$$
H^{2 i}\left(X_{2 i-1} ; Z\right) \in \mathfrak{S}(X, 2 i-1) .
$$

REMARKS. This proposition clearly holds for spaces whose even dimensional homotopy groups are finite. Furthermore, under suitable hypotheses, remarks of this sort may be made about other characteristic classes. Details are left to the reader.

\section{BIBLIOGRAPHY}

1. A. Borel, and J-P. Serre, Groupes de Lie et Puissaines Reduits de Steenrod, Amer. J. Math. (1953).

2. D. W. Kahn, Induced maps for Postnikov Systems, Trans. Amer. Math. Soc. 107, 3 (1963).

3. J-P. Serre, Groupes d'Homotopie et Classes des Groupes Abelians, Annals of Math. 58, 2 (1953).

4. - Homologie Singuliere des Espaces Fibres, Annals of Math. 54, 3 (1951).

5. J. H. C. Whitehead, Combinatorial Homotopy I, Bull. Amer. Math. Soc. 55, 3 (1949). 


\title{
PACIFIC JOURNAL OF MATHEMATICS
}

\author{
EDITORS
}

\author{
H. Samelson \\ Stanford University \\ Stanford, California \\ R. M. Blumenthal \\ University of Washington \\ Seattle, Washington 98105
}

\author{
J. DugundjI \\ University of Southern California \\ Los Angeles, California 90007 \\ Richard Arens \\ University of California \\ Los Angeles, California 90024
}

\section{ASSOCIATE EDITORS}
E. F. BECKENBACH
B. H. NEUMaNN
F. WOLF
K. YosIDA

\section{SUPPORTING INSTITUTIONS}

\author{
UNIVERSITY OF BRITISH COLUMBIA \\ CALIFORNIA INSTITUTE OF TECHNOLOGY \\ UNIVERSITY OF CALIFORNIA \\ MONTANA STATE UNIVERSITY \\ UNIVERSITY OF NEVADA \\ NEW MEXICO STATE UNIVERSITY \\ OREGON STATE UNIVERSITY \\ UNIVERSITY OF OREGON \\ OSAKA UNIVERSITY \\ UNIVERSITY OF SOUTHERN CALIFORNIA
}

\author{
STANFORD UNIVERSITY \\ UNIVERSITY OF TOKYO \\ UNIVERSITY OF UTAH \\ WASHINGTON STATE UNIVERSITY \\ UNIVERSITY OF WASHINGTON \\ AMERICAN MATHEMATICAL SOCIETY \\ CALIFORNIA RESEARCH CORPORATION \\ SPACE TECHNOLOGY LABORATORIES \\ NAVAL ORDNANCE TEST STATION
}

Mathematical papers intended for publication in the Pacific Journal of Mathematics should by typewritten (double spaced). The first paragraph or two must be capable of being used separately as a synopsis of the entire paper. It should not contain references to the bibliography. Manuscripts may be sent to any one of the four editors. All other communications to the editors should be addressed to the managing editor, Richard Arens, at the University of California, Los Angeles, California 90024.

50 reprints per author of each article are furnished free of charge; additional copies may be obtained at cost in multiples of 50 .

The Pacific Journal of Mathematics is published quarterly, in March, June, September, and December. Effective with Volume 13 the price per volume (4 numbers) is $\$ 18.00$; single issues, $\$ 5.00$. Special price for current issues to individual faculty members of supporting institutions and to individual members of the American Mathematical Society: $\$ 8.00$ per volume; single issues $\$ 2.50$. Back numbers are available.

Subscriptions, orders for back numbers, and changes of address should be sent to Pacific Journal of Mathematics, 103 Highland Boulevard, Berkeley 8, California.

Printed at Kokusai Bunken Insatsusha (International Academic Printing Co., Ltd.), No. 6, 2-chome, Fujimi-cho, Chiyoda-ku, Tokyo, Japan.

PUBLISHED BY PACIFIC JOURNAL OF MATHEMATICS, A NON-PROFIT CORPORATION

The Supporting Institutions listed above contribute to the cost of publication of this Journal, but they are not owners or publishers and have no responsibility for its content or policies. 


\section{Pacific Journal of Mathematics}

\section{Vol. 15, No. $2 \quad$ October, 1965}

Patrick Robert Ahern, On the generalized F. and M. Riesz theorem......... 373

A. A. Albert, On exceptional Jordan division algebras ................ 377

J. A. Anderson and G. H. Fullerton, On a class of Cauchy exponential

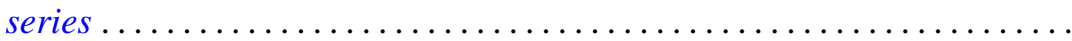

Allan Clark, Hopf algebras over Dedekind domains and torsion in

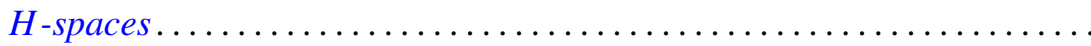

John Dauns and D. V. Widder, Convolution transforms whose inversion functions have complex roots .............................

Ronald George Douglas, Contractive projections on an $\mathrm{L}_{1}$ space ..........

Robert E. Edwards, Changing signs of Fourier coefficients ...............

Ramesh Anand Gangolli, Sample functions of certain differential processes on symmetric spaces .....................................

Robert William Gilmer, Jr., Some containment relations between classes of

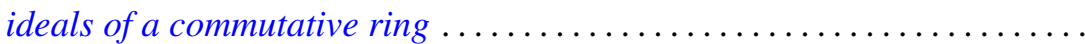

Basil Gordon, A generalization of the coset decomposition of a finite

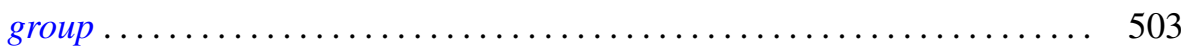

Teruo Ikebe, On the phase-shift formula for the scattering operator....... 511

Makoto Ishida, On algebraic homogeneous spaces ................ 525

Donald William Kahn, Maps which induce the zero map on homotopy ........ 537

Frank James Kosier, Certain algebras of degree one ................. 541

Betty Kvarda, An inequality for the number of elements in a sum of two sets of lattice points.................................

Jonah Mann and Donald J. Newman, The generalized Gibbs phenomenon for regular Hausdorff means. .

Charles Alan McCarthy, The nilpotent part of a spectral operator. II . ...

Donald Steven Passman, Isomorphic groups and group rings ...

R. N. Pederson, Laplace's method for two parameters .....

Tom Stephen Pitcher, A more general property than domination for sets of probability measures .............................

Arthur Argyle Sagle, Remarks on simple extended Lie algebras. .

Arthur Argyle Sagle, On simple extended Lie algebras over fields of

characteristic zero.

Tôru Saitô, Proper ordered inverse semigroups ...........

Oved Shisha, Monotone approximation

Indranand Sinha, Reduction of sets of matrices to a triangular form

Raymond Earl Smithson, Some general properties of multi-valued

functions .................................

John Stuelpnagel, Euclidean fiberings of solvmanifolds .... 